\title{
Análise da linguagem de textos de divulgação científica em livros didáticos: contribuições para o ensino de biologia
}

\section{Language analyses of popular science texts in textbooks: contributions to Biology teaching}

\author{
Pedro Henrique Ribeiro de Souza ${ }^{1}$. Marcelo Borges Rocha $^{1}$
}

\begin{abstract}
Resumo: A utilização de textos de Divulgação Científica (DC) no Ensino de Ciências consiste em prática estimulada por diversos autores para contextualizar o conteúdo escolar. Por ser voltada ao público não especializado, a DC articula discursos científico e didático, facilitando sua leitura. Livros didáticos de Ciências e de Biologia apresentam textos de DC, selecionados para diversificar suas fontes de informação. Este trabalho analisou linguagem e discurso de 17 textos de DC sobre Biologia Animal, presentes em cinco coleções didáticas de Biologia para o Ensino Médio. Constatou-se preferência por textos mais didáticos ou com equilíbrio dos traços de didaticidade, cientificidade ou laicidade. Identificou-se analogias e metáforas, auxiliando na explicação de termos científicos, e poucos erros conceituais. Conclui-se que a articulação entre DC e Ensino de Biologia, promovida pelos livros didáticos, pode contribuir para a formação de leitores, cabendo aos professores lerem e selecionarem textos mais adequados às suas aulas.
\end{abstract}

Palavras-chave: Divulgação científica. Livro didático. Ensino de biologia.

\begin{abstract}
The use of popular science texts in science education is encouraged by several authors to contextualize the school content. Dedicated to non-experts, popular science articulates both didactic and scientific discourses, making them easier to read. Science and Biology textbooks have popular science texts, selected to diversify their sources of information. This study analysed language and discourse of 17 popular science texts of Animal Biology, from five didactic collections of Biology for Secondary Education. There is preference for texts that are more didactic or with a balance of didactic, scientific and secular traits. We identified analogies and metaphors, which help in the explanation of scientific terms, and a few misconceptions. We conclude that the relationship between popular science and Biology Education, promoted by textbooks, can contribute to the formation of readers; it is up to the teacher to read and select texts that best fit their classes.
\end{abstract}

Keywords: Popular science. Textbooks. Biology teaching.

\footnotetext{
${ }^{1}$ Centro Federal de Educação Tecnológica Celso Suckow da Fonseca (CEFET), Rio de Janeiro, RJ, Brasil. E-mail: <pedrohrsouza@hotmail.com>.
} 


\section{Introdução}

A Divulgação Científica (DC) tem como pressuposto básico garantir o acesso da população aos conhecimentos da ciência e da tecnologia, percebendo seus impactos na sociedade e no ambiente. Com isso, é fundamental reconhecer a importância da problematização, ampliação e aperfeiçoamento das atividades de DC, o que permite a democratização dos conhecimentos científicos e tecnológicos. (SOUZA; ROCHA, 2015a).

O uso de textos de DC no âmbito do Ensino de Ciências possibilita a inclusão dos cidadãos em debates que lidem com temas específicos da ciência e da tecnologia, com potencial impacto em suas vidas e trabalho. Neste bojo, encontrar-se-iam os avanços da Engenharia Genética, como produção de alimentos transgênicos e pesquisas com células tronco, além de assuntos com viés ecológico, como mudanças climáticas, fontes de energias renováveis, etc.

Periódicos como o "Public Understanding of Science", "International Journal of Science and Education" e "Science Education" demonstram a importância e preocupação com a forma como a educação formal e a DC se relacionam (NASCIMENTO; REZENDE JR., 2010). Millar (1996) confronta o currículo das ciências na educação básica com a falta de entendimento básico dos principais conceitos científicos pela maioria dos estudantes. Para tal, justifica que ensinar ciências baseia-se em cinco argumentos: o econômico, que visa a melhoria econômica do país; o utilitário, para entender o funcionamento do mundo ao redor; o democrático, pois permitiria a população participar de debates e discussões acerca de assuntos científicos e tecnológicos; o social, devido aos impactos sociais gerados por ciência e tecnologia; e o cultural, entendendo que ciência e tecnologia fazem parte da cultura humana. Desta maneira, o autor considera importante valorizar a DC para otimizar a compreensão de como a ciência e a tecnologia operam, suas forças internas e externas e seus impactos sociais.

Parkinson e Adendorff (2004) investigam a utilização de artigos de DC no Ensino de Ciências e, comparando as características do discurso da DC de um artigo acadêmico e de um livro didático - os dois últimos tendo como alvo os alunos -, concluíram que os artigos de DC não servem de modelo a respeito do que é a escrita científica. No entanto, sugere-se que estes podem tornar a ciência mais acessível para os alunos e, por isso, podem desempenhar um papel útil no ensino da escrita científica, bem como no ensino das ciências. Isto ocorre porque os artigos de DC visualizam as descobertas científicas como provisórias, em vez de fatos incontroversos como são apresentados nos livros didáticos ou como são abordados em artigos científicos. Outra característica ressaltada pelos autores a respeito dos artigos de DC é que estes podem ser escritos por cientistas, sendo retratados como pessoas comuns e não como "gênios", como são percebidos por certos livros didáticos ou pelo senso comum.

No Brasil, recomenda-se a utilização da DC em sala de aula, conforme sugerem os Parâmetros Curriculares Nacionais (BRASIL, 2000), enquanto fontes de conhecimento além do livro didático. A utilização destes textos também é defendida por diversos autores na literatura (e.g. GONÇALVES; CALDAS; PECHULA, 2011; MARTINS; CASSAB; ROCHA, 2001; ROCHA, 2010), por representar uma forma de contextualização dos conhecimentos científicos inerentes aos conteúdos disciplinares, incentivo à prática da leitura de textos científicos, familiarização com terminologias e conceitos científicos e compreensão da natureza da atividade científica. Cabe ressaltar que é fundamental a participação dos professores na seleção e adaptação destes textos, adequando-os a diferentes contextos pedagógicos. 
Dentre os trabalhos acadêmicos que relacionam DC e Ensino de Ciências, encontramse os que investigam como os textos de DC podem ser reelaborados na inserção em livros didáticos de Ciências (MARTINS; CASSAB; ROCHA, 2001; MARTINS; DAMASCENO, 2002; NASCIMENTO, 2005; SOUZA; ROCHA, 2014b) ou na aplicação em sala de aula em atividades realizadas com professores em formação (MARTINS; NASCIMENTO; ABREU, 2004; NASCIMENTO, 2008). Outros trabalhos relevantes buscaram a opinião de professores a respeito de como estes usam textos de DC em suas aulas (GOMES; DA POIAN; GOLDBACH, 2012; ROCHA, 2010) ou realizaram levantamentos do estado da arte das produções acadêmicas sobre a utilização de DC em sala de aula apresentadas em congressos relevantes da área ou em periódicos e outras produções acadêmicas (FERREIRA; QUEIROZ, 2012a; NASCIMENTO; REZENDE JR., 2010; SOUZA; ROCHA, 2014a).

$\mathrm{Na}$ literatura, também é possível encontrar trabalhos acadêmicos cuja finalidade é analisar artigos de DC com enfoque em certas temáticas cientificas, como Genética (GÓES; OLIVEIRA, 2014; GOLDBACH; EL-HANI, 2008; GOLDBACH; EL-HANI; MARTINS, 2005; MASSARANI; MOREIRA, 2008; SOUSA et al., 2014), Biologia Celular (LEGEY; JURBERG; COUTINHO, 2009), Microbiologia (FRAGA; ROSA, 2015), Evolução (KEMPER; ZIMMERMAN; GASTAL, 2010), Saúde (LOBO; MARTINS, 2013; OLIVEIRA et al., 2010), Meio Ambiente (DAL PIAN; ALVES, 2013; GARRÉ; HENNING, 2015; JORGE; ESCOLANO; CASSIOLATO, 2011; PEREIRA; TERRAZZAN, 2011; SULAIMAN, 2011), Física (GOMES; FUSINATO; NEVES, 2010; MUSSATO; CATELLI, 2015), Química (FERREIRA; QUEIROZ, 2012b; QUEIROZ; FERREIRA, 2013) e Sistemática Filogenética (SOUZA; ROCHA, 2015b). Em comum, os autores salientaram as distorções que ocorrem na transposição didática, isto é, na passagem de uma linguagem científica para uma mais próxima de um público não especialista, identificando o uso de analogias, metáforas e erros conceituais.

O objetivo deste trabalho é analisar, sob a luz da Análise do Discurso, textos de DC inseridos em livros didáticos de Biologia do Ensino Médio, com o intuito de verificar: o tipo de linguagem adotado; a utilização de analogias e metáforas; e a presença de erros conceituais. O livro didático foi escolhido por se tratar de um material com finalidades estritamente pedagógicas, incluindo em seu cerne textos de DC escolhidos com a finalidade de contextualizar o conteúdo didático. Com isto, o propósito é entender de que maneira estes textos são construídos, o que e como falam, possibilitando a compreensão das características do discurso da DC que interessam aos autores dos livros didáticos de Biologia do Ensino Médio com a finalidade de contextualizar os conteúdos didáticos abordados em suas coleções.

\section{Discurso da Divulgação Científica}

Para Fourez (1995), a divulgação da ciência pode se dar para o grande público como um efeito vitrine, focando nas "maravilhas da ciência", ou pela transmissão de poder social, transmitindo certo conhecimento científico e tecnológico útil no entendimento de questões tecnocientíficas. Cabe ao discurso subjacente à fala do divulgador da ciência definir qual destas maneiras será a predominante na apresentação de algum acontecimento científico pelos órgãos midiáticos. Neste âmbito, o discurso da DC pode ser entendido como a união dos discursos científico, jornalístico e cotidiano, indicando a ocorrência de uma "metaforização" dos discursos 
científico e jornalístico na relação com o cotidiano. A DC está sujeita a determinadas condições de produção, responsáveis pelas relações de força em seu discurso, que definem as posições do enunciador e destinatário, o tratamento a ser dado no assunto e a construção composicional, além de considerar a não-transparência da linguagem, na qual o discurso carrega uma materialidade simbólica própria e significativa. (ORLANDI, 2001, 2002).

Zamboni (2001, p. 96) identifica uma "superposição de traços de cientificidade, laicidade e didaticidade, que se deixam mostrar, em graus variados, na superfície dos textos”. Entendendo os traços de cientificidade como oriundos do discurso científico, relacionados tanto à práxis científica como a possíveis consequências negativas de produtos da ciência; os traços de laicidade são inerentes ao discurso cotidiano, o que inclui as diferentes formas de contextualização, sejam elas sociais, políticas, econômicas, etc.; e os traços de didaticidade incluem procedimentos como explicações, recapitulações, orientações metodológicas, etc. (FERREIRA; QUEIROZ, 2012b). De forma análoga, Cataldi (2007, p. 158) considera que "ainda que o discurso divulgativo utilize informações procedentes do discurso científico, o modo de elaboração deste novo discurso é específico, pois está determinado por concepções próprias de produção e de difusão”. Ou seja, a elaboração do discurso divulgativo dependerá da intenção de quem o concebe, dos interesses mercadológicos e do público alvo. Assim, observa-se a ocorrência de uma "recontextualização" do conhecimento científico, uma recriação destinada a púbicos específicos, não se tratando de um simples resumo ou redução aleatória de dados científicos, mas uma habilidade em selecionar, reorganizar e reformular informações técnicas para leitores com interesses e objetivos diversos, no processo de compreensão dos fatos científicos. Assim, o divulgador lança mão de uma estratégia divulgativa, na qual utiliza procedimentos léxico-semânticos (sinonímia, paráfrase, definição, descrição, denominação, generalização, etc.), discursivos (contextualização, modalização, etc.) e/ou cognitivos (analogias, metáforas, metonímias, etc.). (CATALDI, 2009).

Para Alferes e Agustini (2008), a vulgarização dos saberes científicos, ao serem transpostos para um público não restrito, pode afetar e transformar a concepção de ciência presente no senso comum vista como forma de conhecimento acumulativo, sistematizável e atemporal. O propósito de transmitir uma visão de ciência neutra e utilitária, relacionada com o bem-estar da sociedade, seria de caráter político, ao privilegiar resultados científicos referentes à tecnologia e à saúde, áreas de maior destaque na sociedade capitalista. Para as autoras, a formação discursiva da DC se origina de um discurso científico, influenciado e alterado por discursos não científicos, ora o discurso jornalístico, caracterizado pela figura do próprio divulgador, ora pelo discurso cotidiano, associado à figura do leitor. Como o divulgador encontra-se no centro e não pode transcender à "verdade" científica e nem à "verdade" da mídia, "o sujeito-jornalista (re) significa os saberes da ordem da ciência e constrói sua identidade comprometido com a linha editorial da revista, com o entendimento do leitor e com a 'verdade' da ciência" (ALFERES; AGUSTINI, 2008, p. 5). Nesta posição de divulgador, identificando o seu dizer aos dizeres dos outros, provoca uma "anulação do próprio 'eu”, ou seja, "coloca-se em um 'lugar secundário do dizer' e produz o efeito de que a sua autoria é, aparentemente, menos significativa”" (ALFERES; AGUSTINI, 2008, p. 6).

Maingueneau (2008) destaca a constituição do Ethos do enunciador, presente no tom, na forma de dizer, de relatar, e que se revela ao leitor por meio da conjunção de diferentes elementos como o estilo da publicação, seu público e seus objetivos comerciais (ethos pré-discursivo) 
e o tom que assume ao elaborar o texto (ethos discursivo). Por ser um texto que necessita de apelos para persuadir seus leitores, o texto de DC utiliza estratégias diferenciadas de composição enunciativa ou de cenas de enunciação, através dos quais o ethos é parte constituinte: "Por meio do ethos, o destinatário está, de fato, convocado a um lugar, inscrito na cena de enunciação que o texto implica. Essa 'cena de enunciação' compõe-se de três cenas, que propus chamar 'cena englobante', 'cena genérica' e 'cenografia”' (MAINGUENEAU, 2008, p. 70). No âmbito da DC, a cena englobante é a que caracteriza os textos como pertencentes a esta área temática; a cena genérica está relacionada à DC em veículo ou revista especializados; e a cenografia depende de cada reportagem, através dos recursos diferentes de composição, de apresentação e de inserção do ethos que o divulgador seleciona. (GONÇALVES, 2013).

Para Charaudeau (2003), a mídia produz signos que constroem um sentido social (lógica semiológica) em um contexto econômico, onde a informação se torna um bem de consumo (lógica econômica). Portanto, sob esta ótica discursiva

o enunciado não deve ser abordado isoladamente do seu contexto enunciativo, que envolve desde as condições de produção até as possíveis condições de recepção, passando, evidentemente pelo conteúdo a ser veiculado e pelo impacto que as informações científicas e/ou tecnológicas possam ter para a sociedade. (GONÇALVES, 2013, p. 221).

Face ao exposto, cabe discutir se a DC apresentada nos materiais pedagógicos como os livros didáticos, ao apresentarem aos alunos textos e imagens produzidos pela mídia, podem promover condições para sua alfabetização científica e tecnológica e para sua formação como cidadão crítico e consciente.

\section{Textos de Divulgação Científica em Livros Didáticos}

O livro didático é objeto fundamental adotado no processo da educação e pode ser caracterizado por ser uma obra aberta, que deve dialogar com outros tipos de saberes, como os da comunidade científica. A instituição do livro didático pelo Ministério da Educação data da década de 1930, considerado no período como uma importante ferramenta de educação política e ideológica, com o Estado atuando como censor ao uso deste material didático (MEGID-NETO; FRACALANZA, 2003; BELTRÁN NÚÑEZ et al., 2003). Sua adoção norteia o currículo a ser seguido, pois é escrito por autores que muitas vezes são especialistas em determinadas áreas, o que os torna competentes neste ofício. Porém, frequentemente o que é escrito nos livros didáticos de Ciências encontra barreiras de natureza epistemológica, seja esbarrando na complexidade dos fenômenos científicos ou na falta de linguagem e de outros recursos que tornem acessíveis as informações para os alunos. Em muitas escolas no Brasil, o livro didático é o único material didático que o professor possui, além de uma lousa com giz, servindo de base para o próprio professor se planejar e conduzir a sua aula.

Os autores de livros didáticos cada vez mais utilizam em suas obras uma diversidade de fontes de informação, além do texto que desenvolve o conteúdo, como imagens, infográ- 
ficos, exercícios e textos escritos por outros autores, como os textos de DC. Estes podem ser distribuídos nestas obras, servindo de motivação, de contextualização e de complementação aos conteúdos detalhados nos diferentes capítulos. Porém, é importante entender por que e de que forma tais textos são selecionados e adaptados ao serem inseridos nos livros didáticos.

Trabalhos como o de Martins, Cassab e Rocha (2001), Nascimento (2005) e Souza e Rocha (2014a) analisaram casos de reelaboração discursiva de textos de DC inseridos em livros didáticos de Biologia e de Ciências. Estas alterações envolvem operações de eliminação, reordenação, substituição e acréscimo, de maneira a tornar a linguagem do texto compatível para os alunos do nível de ensino para qual o livro didático é destinado. Em consenso, houve redução significativa de informação, com modificação da visão de natureza da ciência transmitida pelo texto, indicando que este apresentava caráter composicional no livro didático, com a finalidade de contextualizar um determinado conteúdo.

Galieta (2013) comparou um texto de DC com um texto presente em um livro didático de Ciências do Ensino Fundamental, que tratavam do mesmo assunto, valendo-se da Análise do Discurso de linha francesa. A autora percebeu que há uma diferença significativa entre os discursos do texto didático, caracterizado pelos discursos científico e pedagógico, e o do texto de DC, que se relaciona mais com o discurso cotidiano, recorrendo ao discurso científico ao necessitar de maiores explicações científicas.

Martins e Damasceno (2002) analisaram seis coleções de livros didáticos e constataram a presença de 83 textos escritos ou imagéticos de DC, sendo a maioria (84\%) proveniente de jornais e revistas de divulgação. Na maior parte dos livros, o texto de DC foi colocado ao lado com o texto principal, porém sem haver sugestões para uma leitura que os relacionasse. Os autores também destacaram que a maioria dos textos de divulgação incorporados aos livros analisados sofreu alguma espécie de adaptação, sugerindo um esforço de didatização destes textos. No que tange à preferência por jornais e revistas de DC como fontes principais de material a serem incorporados nos livros didáticos, os autores entendem que isto atende a um critério de atualidade para as informações contidas no texto. Desta forma, a credibilidade das informações é conferida, muitas vezes, por meio de citações de especialistas ao longo do texto.

Souza e Rocha (2015a) realizaram uma caracterização dos 398 textos de DC encontrados em nove coleções de livros didáticos de Biologia do Ensino Médio e perceberam uma quantidade significativa de textos abordando assuntos ecológicos, zoológicos e evolutivos, com discreta quantidade daqueles que tratavam de Genética e Biologia Molecular, áreas bastante relevantes na pesquisa científica atual. A maior parte dos textos sofreu algum tipo de adaptação, como edições, traduções ou reelaborações discursivas, sendo retirada de fontes como jornais e revistas especializadas em DC. Por fim, os autores constataram que a maioria foi escrita por jornalistas, porém sendo comum encontrar textos escritos por cientistas interessados em divulgar ciência para o público leigo.

Diante deste cenário, optou-se por realizar uma pesquisa que envolvesse estes dois grandes atores que são bastante comentados e trabalhados no Ensino de Ciências: a DC e o Livro Didático. Cabe ressaltar que os livros didáticos de Biologia apresentam outras formas de relacionar estas duas entidades que não apenas através de textos midiáticos, mas também com sugestões de filmes, documentários, museus e centros de ciência. 


\section{Metodologia}

Este trabalho tem como fonte de dados cinco coleções de livros didáticos de Biologia do Ensino Médio selecionadas a partir do Programa Nacional do Livro Didático (PNLD) (BRASIL, 2014). Cada coleção é composta por três livros, cada um destinado a uma determinada série do Ensino Médio. Foram analisadas as coleções "Biologia em Contexto" (AMABIS; MARTHO, 2013), "Conexões em Biologia (BRÖCKELMANN, 2013), "Biologia" (CÉSAR JR.; SEZAR; CALDINI JR., 2013), "Biologia Unidade e Diversidade” (FAVARETTO, 2013) e "Bio" (LOPES; ROSSO, 2013).

As coleções analisadas foram acessadas durante o processo de escolha dos livros didáticos em escolas públicas do Rio de Janeiro, no ano de 2014. A pesquisa se deu com a leitura minuciosa das coleções, que percorreu todas as páginas de cada coleção, buscando textos oriundos da mídia impressa ou digital, como jornais, revistas, portais da internet ou de instituições de pesquisa científica. Estas mesmas coleções foram utilizadas em trabalho anteriormente descrito, que identificou e caracterizou os textos de DC presentes. (SOUZA; ROCHA, 2015a).

Para este trabalho, objetivou-se analisar 17 textos de DC que apresentaram aspectos relacionados à Biologia Animal, adotando a Análise do Discurso e os conceitos de Zamboni (2001) acerca dos diferentes graus de cientificidade, didaticidade e laicidade. Também foram analisadas as metáforas e analogias, utilizando o conceito de metáfora de Brown (2003, p. 15, tradução nossa), que a define como "o acoplamento interativo entre modelo, teoria e observação que caracteriza a formulação e o teste de hipóteses e teorias". Hernando (2003, apud GOLDBACH; EL-HANI, 2008, p. 166) ratifica a importância das metáforas, pois são um recurso importante para explicar, comunicar e persuadir a audiência dos textos de DC.

Neste estudo, optou-se por analisar os originais dos textos que foram inseridos nos livros didáticos, encontrados em sites da internet cujos links estavam disponíveis nos próprios livros didáticos (com exceção dos textos CE02 e LP01, disponíveis apenas nas versões impressas, que foram consultadas para este estudo), de forma a entender o que despertou o interesse dos autores das coleções didáticas em selecioná-los. Estes textos eram alocados em três diferentes locais dos livros: no início dos capítulos, como motivadores; ao longo do capítulo, relacionado a algum assunto desenvolvido no texto didático; ou ao fim do capítulo, para contextualizar o conteúdo didático. O Quadro 1 reúne as principais informações a respeito dos textos analisados. 
Quadro 1. Lista dos 17 textos de DC analisados

\begin{tabular}{|c|c|c|c|c|}
\hline \multicolumn{5}{|l|}{ Amabis e Martho (2013) } \\
\hline Localização no livro & Código e Título & Autor(es) & Fonte & Data \\
\hline v. 1, cap. 6, p. 109 & $\begin{array}{l}\text { AM01 - A falta dos } \\
\text { grandes predadores }\end{array}$ & $\begin{array}{l}\text { Não } \\
\text { informado }\end{array}$ & Agência FAPESP & $19 / 07 / 2011$ \\
\hline $\begin{array}{l}\text { v. } 2 \text {, cap. } 10, \text { p. } 276: \text { A origem } \\
\text { de novas espécies e dos } \\
\text { grandes grupos de seres vivos }\end{array}$ & $\begin{array}{l}\text { AM02 - Observando o } \\
\text { surgimento de uma nova } \\
\text { espécie }\end{array}$ & $\begin{array}{l}\text { Fernando } \\
\text { Reinach } \\
\text { (biólogo) }\end{array}$ & $\begin{array}{l}\text { O Estado de S. } \\
\text { Paulo }\end{array}$ & $16 / 10 / 2008$ \\
\hline $\begin{array}{l}\text { v. 2, cap. 11, p. 307-308: } \\
\text { Evolução humana }\end{array}$ & $\begin{array}{l}\text { AM03 - Ancestral } \\
\text { humano já andava ereto, } \\
\text { mas preferia viver em } \\
\text { árvores }\end{array}$ & $\begin{array}{l}\text { Cesar Baima } \\
\text { (jornalista) }\end{array}$ & O Globo & $26 / 08 / 2012$ \\
\hline $\begin{array}{l}\text { v. 3, cap. } 5 \text {, p. 111: } \\
\text { Reprodução e } \\
\text { desenvolvimento das } \\
\text { angiospermas }\end{array}$ & $\begin{array}{l}\text { AM04 - Declínio de } \\
\text { insetos polinizadores } \\
\text { ameaça lavouras em todo } \\
\text { o mundo }\end{array}$ & \begin{tabular}{|l} 
Maria \\
Fernanda \\
Ziegler \\
(jornalista) \\
\end{tabular} & O Dia & $01 / 03 / 2013$ \\
\hline \multicolumn{5}{|l|}{ Bröckelmann (2013) } \\
\hline Localização no livro & Código e Título & Autores & Fonte & Data \\
\hline $\begin{array}{l}\text { v. 2, unidade 4, p. 156: } \\
\text { Invertebrados }\end{array}$ & $\begin{array}{l}\text { BR01 - Tratores auxiliam } \\
\text { barcos na pesca na praia } \\
\text { do farol }\end{array}$ & $\begin{array}{l}\text { Juliana Briggs } \\
\text { (jornalista) }\end{array}$ & G1 - Globomar & $05 / 04 / 2012$ \\
\hline $\begin{array}{l}\text { v. 2, unidade 5, p. 193: } \\
\text { Cordados }\end{array}$ & $\begin{array}{l}\text { BR02 - A matemática da } \\
\text { proteção }\end{array}$ & $\begin{array}{l}\text { Juliana } \\
\text { Tinoco } \\
\text { (jornalista) }\end{array}$ & Ciência Hoje & $24 / 08 / 2006$ \\
\hline $\begin{array}{l}\text { v. 3, unidade 4, p. 150: } \\
\text { Evolução das espécies }\end{array}$ & $\begin{array}{l}\text { BR03 - O terrível } \\
\text { crocodilo de Uberaba }\end{array}$ & $\begin{array}{l}\text { Marina } \\
\text { Pereira } \\
\text { Queiróz } \\
\text { (jornalista) } \\
\end{array}$ & $\begin{array}{l}\text { Revista Minas faz } \\
\text { Ciência }\end{array}$ & $\begin{array}{l}\text { Jun.-ago. } \\
2005\end{array}$ \\
\hline \multicolumn{5}{|c|}{ César Jr., Sezar e Caldini Jr. (2013) } \\
\hline Localização no livro & Código e Título & Autores & Fonte & Data \\
\hline $\begin{array}{l}\text { v. } 2 \text {, cap. } 8 \text {, p. } 75 \text { : Moluscos e } \\
\text { equinodermos }\end{array}$ & $\begin{array}{l}\text { CE01 - Ostra também é } \\
\text { cultura }\end{array}$ & $\begin{array}{l}\text { Célio Yano } \\
\text { (jornalista) }\end{array}$ & Ciência Hoje & $26 / 01 / 2006$ \\
\hline $\begin{array}{l}\text { v. } 2 \text {, cap. } 12 \text {, p. 107-108: Os } \\
\text { anfíbios }\end{array}$ & $\begin{array}{l}\text { CE02-Com os pés em } \\
\text { terra firme }\end{array}$ & $\begin{array}{l}\text { Jennifer } \\
\text { A. Clack } \\
\text { (zoóloga) }\end{array}$ & $\begin{array}{l}\text { Scientific } \\
\text { American Brasil }\end{array}$ & Jan. 2006 \\
\hline $\begin{array}{l}\text { v. } 3 \text {, cap. } 21, \text { p. } 281: \text { Os } \\
\text { vermes parasitas do ser } \\
\text { humano }\end{array}$ & CE03-Chorume suíno & $\begin{array}{l}\text { Xico } \\
\text { Graziano } \\
\text { (engenheiro } \\
\text { agrônomo) }\end{array}$ & $\begin{array}{l}\text { O Estado de S. } \\
\text { Paulo }\end{array}$ & $29 / 01 / 2008$ \\
\hline
\end{tabular}


Análise da linguagem de textos de divulgação científica ...

Quadro 1. continuação

\begin{tabular}{|c|c|c|c|c|}
\hline \multicolumn{5}{|l|}{ Favaretto (2013) } \\
\hline Localização no livro & Código e Título & Autores & Fonte & Data \\
\hline $\begin{array}{l}\text { v. 2, cap. 5, p. 96: Vida } \\
\text { e diversidade animal - } \\
\text { Invertebrados I }\end{array}$ & $\begin{array}{l}\text { FA01 - Queimaduras com } \\
\text { água-viva se multiplicam } \\
\text { nas praias do Paraná }\end{array}$ & $\begin{array}{l}\text { Não } \\
\text { informado }\end{array}$ & G1 & $23 / 01 / 2012$ \\
\hline $\begin{array}{l}\text { v. 2, cap. } 7, \text { p. 121: Vida } \\
\text { e diversidade animal - } \\
\text { Invertebrados II }\end{array}$ & $\begin{array}{l}\text { FA02 - Instituto Butantan } \\
\text { identifica } 17 \text { novas } \\
\text { espécies de aranha }\end{array}$ & $\begin{array}{l}\text { Bruno Deiro } \\
\text { (jornalista) }\end{array}$ & $\begin{array}{l}\text { O Estado de S. } \\
\text { Paulo }\end{array}$ & $07 / 08 / 2012$ \\
\hline $\begin{array}{l}\text { v. 2, cap. 8, p. 152: Vida e } \\
\text { diversidade animal - Cordados }\end{array}$ & $\begin{array}{l}\text { FA03 - Neandertal era tão } \\
\text { esperto quanto o Homo } \\
\text { sapiens }\end{array}$ & $\begin{array}{l}\text { Salvador } \\
\text { Nogueira } \\
\text { (jornalista) }\end{array}$ & Superinteressante & Jan. 2012 \\
\hline $\begin{array}{l}\text { v. } 3 \text {, cap. } 2 \text {, p. } 41 \text { : } \\
\text { Comunidades- interações e } \\
\text { adaptações }\end{array}$ & $\begin{array}{l}\text { FA04 - Borboleta induz } \\
\text { formiga a cuidar de seus } \\
\text { filhotes }\end{array}$ & $\begin{array}{l}\text { Não } \\
\text { informado }\end{array}$ & $\begin{array}{l}\text { O Estado de S. } \\
\text { Paulo }\end{array}$ & $03 / 01 / 2008$ \\
\hline $\begin{array}{l}\text { v. 3, cap. 16, p. 316-317: } \\
\text { Evolução - ideias e evidências }\end{array}$ & $\begin{array}{l}\text { FA05 - Cachorro surgiu } \\
\text { no Oriente Médio, mostra } \\
\text { análise de DNA }\end{array}$ & $\begin{array}{l}\text { Ricardo } \\
\text { Mioto } \\
\text { (jornalista) }\end{array}$ & Folha de S. Paulo & $18 / 03 / 2010$ \\
\hline \multicolumn{5}{|l|}{ Lopes e Rosso (2013) } \\
\hline Localização no livro & Código e Título & Autores & Fonte & Data \\
\hline $\begin{array}{l}\text { v. 3. cap. 9, 182-183: Origem, } \\
\text { evolução e características } \\
\text { gerais dos animais }\end{array}$ & $\begin{array}{l}\text { LP01 - O maior bioma do } \\
\text { mundo }\end{array}$ & $\begin{array}{l}\text { Herton } \\
\text { Escobar } \\
\text { (jornalista) } \\
\end{array}$ & $\begin{array}{l}\text { O Estado de S. } \\
\text { Paulo }\end{array}$ & $25 / 11 / 2007$ \\
\hline $\begin{array}{l}\text { v. 3, cap. 13, p. } 270 \text { : } \\
\text { Diversidade animal IV }\end{array}$ & $\begin{array}{l}\text { LP02 - Conheça o } \\
\text { pinguim imperador, } \\
\text { estrela do filme "A marcha } \\
\text { dos pinguins" }\end{array}$ & $\begin{array}{l}\text { Não } \\
\text { informado } \\
\text { (da redação) }\end{array}$ & UOL bichos & $12 / 01 / 2006$ \\
\hline
\end{tabular}

Fonte: elaborado pelos autores.

\section{Resultados e Discussão}

\section{a) Linguagem e discurso}

A linguagem e o discurso dos artigos foram analisados de acordo com a caracterização do discurso da DC apresentando traços de didaticidade, cientificidade e laicidade, conforme proposto por Zamboni (2001) e explicado anteriormente. Neste bojo, identificou-se se os textos apresentavam apenas um destes traços de forma marcante ou se podiam exibir duas diferentes facetas de discurso.

O texto AM01, a respeito da reintrodução de lobos em determinados ecossistemas, serve de exemplo de prevalência do traço didático, conforme é possível identificar no seguinte trecho, ao explicar um conceito científico que pode ser acessível para pessoas com conhecimentos científicos básicos: [AM01] "Com a reintrodução de lobos no parque, passou a ocorrer a recuperação do ecossistema, com as plantas voltando a crescer mais, assim como as populações de outros animais." 
Em trecho seguinte, identifica-se o significado de outra expressão cunhada naquele momento para designar um fenômeno descrito pelo texto: [AM01] "chamam de cascata trófica, no qual a perda no topo da cadeia alimentar impacta enormemente muitas outras espécies de animais e de plantas."

O texto BR03 apresenta um caráter didático ao explorar a possível forma de alimentação associada a características da dentição de um crocodilo fóssil, o que levou à razão pela qual o mesmo foi nomeado:

[BR03] Quando assistimos a documentários sobre a vida dos crocodilos de hoje, temos a impressão de que eles não são grandes predadores devido à sua dificuldade em obter alimento. [...] Seus dentes longos, serrilhados e pontiagudos, indicam que ele era carnívoro. Por esse motivo, o fóssil recebeu o nome de Uberabasuchus terrificus, o terrível crocodilo de Uberaba.

O texto FA02, a respeito do comportamento de aranhas, explica alguns termos que poderiam ser restritos à maioria das pessoas, porém utilizando o português de Portugal:

[FA02] Segundo os investigadores, chamam a atenção pela estrutura das quelíceras - espécie de gancho frontal que serve para captura de alimentos e proteção. [...] Uma das hipóteses é o uso na reprodução: as estruturas liberariam feromona, uma poderosa hormona da atração sexual. Além disso, podem servir para prender a fêmea durante a cópula.

Cabe ressaltar que nestes casos, os autores optam pela utilização de apostos ou de orações explicativas, que podem ser separadas por vírgulas ou por travessões do resto do texto, para indicar que naquele trecho está ocorrendo a explicação de um termo científico.

O texto AM03, a respeito da descoberta de um fóssil de um possível ancestral do ser humano (batizado de Selam), apresenta maior grau de cientificidade, na utilização de termos e conceitos que somente podem ser compreendidos por cientistas ou não cientistas com um nível relativamente alto de escolaridade, conforme ilustra o seguinte fragmento:

[AM03] [...] as omoplatas de Selam têm características que se assemelham mais às de outros primatas do que às do Homo sapiens, um forte indicativo de que a espécie mantinha um estilo de vida arbóreo. [...] o fóssil estava encapsulado em uma formação de arenito, garantindo sua preservação ao longo de milhões de anos.

Percebe-se que os termos “omoplatas" e "arenito" aparecem sem qualquer explicação, ao mesmo tempo em que opta por utilizar Homo sapiens ao invés de "ser humano" ou de "espécie humana", conferindo maior traço de cientificidade ao texto.

Já os textos de DC com traços marcantes de laicidade apresentam características do discurso cotidiano, contextualizando o assunto e apresentando teor mais econômico, social e político, conforme apresenta o texto CE01, a respeito de maricultura: 
[CE01] Com o apoio da Petrobrás, profissionais de diversas áreas desenvolvem ações de incentivo à atividade artesanal, sem prejudicar a natureza e orientando a exploração de riquezas do mar no sentido da sustentabilidade econômica e ambiental. [...] Isso porque, mesmo com clima propício e extensa área litorânea, o Brasil não é um país desenvolvido no que diz respeito à produção comercial de organismos marinhos. A maricultura aqui praticada ainda não é capaz de gerar renda para as comunidades tradicionais e é muito dependente do extrativismo.

O fragmento anterior menciona questões políticas e econômicas relacionadas com a atividade da maricultura, indicando ao leitor que esta atividade depende do apoio de entidades governamentais para ocorrer.

Em certos textos, é possível identificar um equilíbrio entre uma fala mais didática, trazendo elementos da linguagem cotidiana, com um discurso científico. O texto CE02, a respeito da origem dos animais tetrápodes, é um caso deste discurso híbrido, conforme pode ser visualizado no trecho a seguir: [CE02] "Hoje esse grupo, os tetrápodes, reúne desde pássaros e seus ancestrais dinossauros até lagartos, anfíbios e mamíferos, incluindo a espécie humana."

Neste excerto, nota-se que há a definição do que são os animais tetrápodes, ilustrando com exemplos de representantes conhecidos pela população em geral. Já o fragmento a seguir do mesmo texto possui maior grau de cientificidade, necessitando do entendimento de certas palavras e expressões típicas do discurso científico, além do uso frequente de nomes científicos de animais: [CE02] "O problema era que o registro fóssil pertinente era esparso, consistindo essencialmente de um peixe desse tipo, o Eusthenopteron, e um tetrápode devoniano, o Ichthyostega, já em estágio muito avançado para elucidar as raízes dos tetrápodes."

Em outros casos, os textos incorporam elementos de discurso didático com discurso laico, conforme pode ser visualizado por estes fragmentos do texto BR02. Neste primeiro, percebe-se uma fala com maior caráter didático, explicando, de maneira clara, como uma pesquisa científica ligada à conservação de espécies de aves é realizada: [BR02] "Para concluir quais espécies corriam o risco de desaparecer, foram usados dados como tamanho de população, ameaças enfrentadas por elas e, claro, ações de conservação a que eram expostas."

Já neste fragmento do mesmo texto, estão explicitadas as razões pelas quais este tipo de pesquisa não é realizado no Brasil, devido a fatores políticos e econômicos que influenciam a atividade científica, o que ressalta o caráter laico do texto:

[BR02] O que impossibilita a maior frequência desse tipo de pesquisa, segundo a autora, é a variedade de ações de conservação empregadas e a dificuldade de se medir a biodiversidade. [...] 'Pela primeira vez não se está falando em quantidade de investimento financeiro, ou de quantos hectares foram protegidos, mas de um parâmetro biológico substantivo'.

Em LP01, a respeito da importância da biodiversidade da Amazônia, também é possível encontrar este caráter híbrido entre um discurso didático e um discurso laico, como indicam os seguintes fragmentos: 
[LP01] A Amazônia brasileira tem 1.200 espécies conhecidas de aves. Só num raio de $150 \mathrm{~km}$ de Manaus é possível encontrar 800 delas, mais do que nos Estados Unidos e Canadá juntos (que têm 700). [...] O planejamento de obras e a definição de áreas para conservação, por exemplo, dependem diretamente desse conhecimento. 'Produzimos muitas informações sobre a Amazônia, mas elas não estão organizadas de uma forma prática que possa nos dar respostas rápidas para perguntas importantes', resume José Maria Cardoso da Silva, da ONG Conservação Internacional (CI).

Neste excerto, o texto é didático ao identificar o número de espécies de aves da Amazônia e comparar este valor ao de outros países. Em outra passagem, pondera-se sobre a necessidade de ações governamentais no sentido de auxiliar a atividade científica que estuda a biodiversidade amazônica, o que configura o seu caráter laico.

Estes resultados sugerem uma aproximação com trabalhos encontrados na literatura a respeito da análise de textos de DC observando a presença de traços de cientificidade, didaticidade e laicidade. Jorge, Escolano e Cassiolato (2011) analisaram artigos com temática ambiental presentes nas revistas Veja e Época, percebendo que a primeira apresenta textos com os três tipos de discurso, o que é comum aos materiais de DC. Para os autores, o professor pode utilizá-los em sala de aula como forma de complementar suas aulas, observando a adequação da temática e da linguagem destes textos. Ferreira e Queiroz (2012b) e Queiroz e Ferreira (2013) realizaram análise similar utilizando artigos sobre Química da revista Ciência Hoje, concluindo que, na maioria das vezes, ocorre um equilíbrio entre estes discursos nos textos de DC. Caso algum traço se sobressaia em relação aos demais, essas variações ocorrem de acordo com a natureza do assunto tratado no artigo, com os objetivos dos autores e com a representação que fazem de seus destinatários.

\section{b) Analogias e metáforas}

Em diversos textos analisados, foi possível encontrar analogias e metáforas, seja para facilitar explicações ou para tornar a leitura mais prazerosa, incluindo elementos de humor. No texto AM02, o fragmento a seguir inclui um bom exemplo de analogia para tornar possível a compreensão da incompatibilidade reprodutiva: [AM02] "os dois tipos de peixes (azuis e vermelhos) já são espécies distintas, incapazes de se misturar ( não cruza com uma zebra)."

O fragmento anterior recorre a um exemplo de fácil acesso ao leitor leigo, por mencionar duas espécies de animais conhecidos e parecidos entre si que não realizam endocruzamento, para comparar com os peixes azuis e vermelhos do Lago Vitória.

Já no texto BR01, o impacto do camarão na economia é destacado como na metáfora encontrada no fragmento a seguir: [BR01] "O Globo Mar foi ao litoral norte do Rio de Janeiro para falar de um dos reis dos mares, um rei dos pescados. ”

No texto BR03, a metáfora utilizada entre aspas é elucidada pelo próprio texto, conforme mostra o seguinte fragmento: [BR03] "formação do que denomina 'swat paleontológica', ou seja, uma equipe qualificada para realizar o monitoramento e o salvamento de fósseis em Uberaba." 
É importante destacar que a utilização de aspas mostra ao leitor que o autor do texto optou pela utilização de um termo que não existe na prática, sendo cunhado apenas para elucidar as ações da equipe de paleontólogos.

O texto CE02 apresenta expressões como "intermediário anatômico" e "lacuna morfológica" para indicar que um determinado fóssil esclareceu as relações evolutivas entre peixes e anfíbios, como indicam os seguintes trechos:

[CE02] Embora estivesse provado que esse animal, em muitos aspectos, era exatamente o tipo de intermediário anatômico entre peixes e tetrápodes imaginado pelos especialistas. [...] Ao mesmo tempo, vários peixes quase-tetrápodes foram sendo descobertos, ajudando a preencher a lacuna morfológica existente.

Ambas expressões foram utilizadas para designar fósseis de transição, que apresentam características intermediárias entre dois grupos de organismos. Além disso, a utilização do termo "peixes quase-tetrápodes" reforça a ideia de linearidade da evolução o que configura um problema conceitual ao posicionar os fósseis como possíveis ancestrais dos anfíbios e não como clados (ramos) distintos na árvore filogenética.

Em FA01, a utilização de uma metáfora sobre a presença dos cnidócitos - células urticantes dos cnidários - configura-se um problema conceitual, pois a comparação entre célula e microbolha é bastante simplificadora, conforme ilustra o seguinte trecho: [FA01] "A água-viva tem na parte de baixo microbolhas tóxicas que se desprendem quando elas encalham na areia ou tocam a pele de uma pessoa."

A utilização da expressão pode trazer ao leitor a ideia de uma estrutura que não é biológica, como o que de fato são os cnidócitos ou nematocistos. Além disso, a utilização da palavra "tóxica" remete a alguma substância química prejudicial à saúde humana, o que pode reduzir a empatia dos humanos por estes animais, sem considerar sua importância ecológica nos ecossistemas marinhos.

Em FA03, a utilização de metáforas confere humor ao texto, pois torna a linguagem mais próxima da cotidiana, reduzindo a complexidade da relação entre os Homo sapiens e os Homo neandertalensis, conforme ilustrado no seguinte trecho: [FA03] "Ou, pelo menos, foi bem chato para os neandertais, [...] liberando a Terra inteira para nós, os Homo sapiens.”

Nesta passagem, a utilização de termos como "foi bem chato" e "liberando a Terra para nós" aproxima o autor do texto ao leitor, introduzindo características dialógicas coloquiais a um texto primariamente de caráter científico. Ao mesmo tempo em que pode despertar o interesse do leitor, este tipo de ocorrência pode trazer consigo problemas conceituais como extrapolar aos neandertais sentimentos do homem moderno, além de premiar o ser humano por ter conquistado a Terra com a extinção dos neandertais.

Em LP02, ocorre uma analogia destacada pelo texto a respeito dos hábitos comportamentais do pinguim imperador: [LP02] "Enquanto crescem, os pingüins ficam reunidos em grupos chamados 'creches.".

A analogia acima foi empregada para aludir à aglomeração de pinguins jovens durante o seu crescimento, sendo o termo cunhado entre aspas para ressaltar ao leitor que não é a correta designação científica para este fenômeno. 
A utilização destes recursos linguísticos por materiais de DC é vista com cautela por pesquisadores da área do Ensino de Ciências. Goldbach e El-Hani (2008) investigaram textos sobre Genética em revistas de DC de ampla circulação nacional - Ciência Hoje, Scientific American Brasil, Superinteressante e Galileu -, observando a presença de analogias e metáforas atribuídas ao código genético. Para os autores, esse uso deve ocorrer de forma cuidadosa, pois "as diferenças entre os campos semânticos que estão sendo aproximadas superam as similaridades que se está procurando destacar" (GOLDBACH; EL-HANI, 2008, p. 180). Souza e Rocha (2015b) discutiram a ocorrência de analogias e metáforas em textos com enfoque na Sistemática Filogenética, extraídos da revista Scientific American Brasil, ressaltando que a colocação de tais palavras e expressões podem disseminar erros conceituais graves, prejudicando o aprendizado sobre determinados conceitos importantes em Biologia.

É importante considerar que, dentre os textos que apresentam analogias e metáforas, cinco foram escritos por jornalistas (BR02, BR03, FA01, FA03 e LP02), enquanto os outros dois por cientistas (AM02 e CE02). Entende-se, portanto, que a utilização destes recursos é uma tendência dos autores de DC em geral, para aproximar-se dos seus leitores.

\section{c) Erros conceituais}

É possível encontrar erros conceituais em alguns destes textos, como ocorre no texto AM04, no qual a fala de um agrônomo possui um equívoco, em um texto que trata sobre polinização, conforme ilustra a seguinte passagem: [AM04] "No urucum, ela [a abelha] não consegue tirar o fruto."

Na polinização, as abelhas retiram os grãos de pólen das flores e os carregam até outras flores, atuando em sua reprodução sexuada. Porém, na passagem descrita acima, entende-se que as abelhas seriam dispersoras de suas sementes, alojadas em seus frutos, o que não ocorre.

O texto CE03 apresenta vários erros conceituais a respeito da tênia e das doenças por ela transmitidas, conforme mostra a seguinte passagem:

[CE03] O grande temor da carne de porco nasce, historicamente, da cisticercose. Fuçando em meio à sujeira, o animal acabava ingerindo fezes humanas, contaminadas com parasita. Os ovos da lombriga (Taenia solium), em condições excepcionais, podem migrar para a carne do porco e, ingeridas por humanos, se encravar nos músculos e, inclusive, no cérebro. Ao eclodirem causam demência e morte. É raríssimo, mas terrível.

O primeiro erro é o nome vulgar da tênia, que pode também ser chamada de solitária, mas nunca de lombriga (o nematódeo Ascaris lombricoides). Além disso, trata a cisticercose como se fosse causada pelo porco, sendo causada na verdade pela ingestão dos ovos, que eclodem e se tornam larvas que podem se deslocar pela circulação, atingindo diferentes órgãos, como músculos e o cérebro. A inserção deste texto foi proposital, pois os autores do livro se aproveitam destes erros para propor uma questão para os alunos: "Ao discorrer sobre a cisticercose, o autor do artigo acima comete vários erros. Aponte-os e indique as correções necessárias em cada caso" (CÉSAR JR.; SEZAR; CALDINI JR., 2013, v. 2, p. 281). Cabe ressaltar que este texto foi escrito por um engenheiro agrônomo, ou seja, alguém que possui formação científica. 
O artigo FA04 apresenta uma concepção incorreta a respeito de evolução pois, quando um organismo de uma espécie adquire uma característica que, após ser submetida à seleção natural, confere alguma vantagem àquela espécie, denominamos este processo de adaptação, que constitui um dos mecanismos do processo evolutivo. Portanto, a utilização da palavra evolução é errônea neste trecho:

[FA04] Mas o trabalho também mostra como as formigas evoluem para escapar dos parasitas, alterando o próprio cheiro. Mas essa saída pela evolução só funciona se as formigas parasitadas não cruzarem com formigas que vivem longe das lagartas e, por isso, não são vítimas do parasita.

Outros textos que apresentaram erros conceituais são o FA02, que considera a aranha um inseto, e FA05 que substitui “árvore filogenética”, utilizada para identificar relações evolutivas entre grupos biológicos, por “árvore genealógica”, expressão cunhada apenas para indicar gerações de indivíduos de uma determinada espécie.

A presença dos erros conceituais em textos de DC é percebida por diversos autores da área do Ensino de Ciências, reforçando a participação do professor no esclarecimento destes equívocos ao utilizá-los em sala de aula (MARTINS; CASSAB; ROCHA, 2001; NASCIMENTO, 2008; SOUZA; ROCHA, 2015b). Kemper, Zimmerman e Gastal (2010), em estudo realizado com textos sobre Evolução das revistas Galileu e Superinteressante, reconheceram a presença de poucos erros conceituais, porém avaliaram como de grande valia esta ocorrência, permitindo aos alunos lerem de forma crítica estes textos, entendendo a dificuldade de transmitir conhecimentos científicos para um público leigo.

No caso desta análise, constatamos que os autores dos livros didáticos suprimiram os fragmentos que apresentam erros conceituais ou epistemológicos (com exceção do texto CE03). Acreditamos que o processo de escolha dos textos baseou-se em seu conteúdo, corrigindo ou não transcrevendo os trechos onde apareceram os erros como forma de não reproduzi-los em suas obras. No entanto, deve-se considerar o porquê destes erros serem frequentes em materiais de DC, pois deveria haver uma preocupação com a correção destes textos pelas linhas editoriais dos jornais, revistas e sites que serviram de fonte para esta pesquisa. Somente na problematização do texto CE03 que é promovida a discussão destes erros com os alunos, o que pode gerar atividades potencialmente ricas de análise destes textos em sala de aula.

\section{Considerações finais}

A inserção de textos oriundos da DC no Ensino de Ciências é uma prática que deve ser estimulada, sobretudo aos autores dos livros didáticos, que tem nas mãos o trabalhoso ofício de transformar o que se sabe sobre Biologia em um manual de três volumes, estruturando-o de forma a atender uma série de exigências epistemológicas e mercadológicas para serem aprovados e adotados pelas escolas públicas brasileiras. Como a ciência é dinâmica, é imprescindível trazer as discussões em Biologia para a ordem do dia, mantendo atualizadas as coleções no curto porém intenso do ponto de vista científico - período de três anos. Deve-se considerar também que estes materiais estão distribuídos pelo país inteiro, onde são instituídos em diferentes re- 
giões socioeconômicas e culturais diferentes, mas que necessitam igualmente de condições que permitam a alfabetização científica e tecnológica de seus estudantes.

A opção dos autores dos livros por textos com linguagem didática, em alguns casos aproximando-se de uma linguagem cotidiana, constitui estratégia para aproximar-se da realidade dos alunos. No entanto, a utilização de textos com linguagem próxima da científica, embora menos frequente, pode representar uma estratégia para que os alunos se apropriem do discurso científico aos poucos. Ao mesmo tempo, a utilização de textos com enfoque laico mostra uma conexão entre as questões científicas e tecnológicas e seus impactos na sociedade e no ambiente, sendo uma estratégia que permite vincular Ciência-Tecnologia-Sociedade e Ambiente ao ensino.

A maior parte dos textos de DC analisados foi redigida por jornalistas, o que pode explicar a grande ocorrência de explicações e usos de analogias e metáforas como recursos para tornar o conteúdo científico mais acessível para o público leigo. Apesar disto, muitos cientistas que escrevem artigos de DC também optaram por utilizar linguagem inteligível para atingir um público mais amplo, o que pode ser verificado em AM02 e CE02. Entende-se, então, que a utilização destes recursos é uma prática comum em autores de DC em geral, com o objetivo de aproximar-se dos seus leitores, facilitando a leitura.

A presença de erros conceituais em vários artigos também revela que seus autores não possuem o mesmo cuidado com a correção das informações científicas, porém isto não foi levado em consideração pelos autores dos livros didáticos, que mantiveram os textos, mas suprimiram estas incorreções. Apenas no caso do texto CE03, por opção dos autores da coleção, foi transcrito um parágrafo contendo inúmeros erros conceituais, com a intenção de servir de base para avaliar os conhecimentos dos alunos em relação aos conteúdos explorados no capítulo onde o texto foi inserido. Também é importante ressaltar que existem textos com erros conceituais atribuídos a jornalistas (FA02 e FA05, por exemplo) ou a profissionais com formação científica, como é o caso do agrônomo no texto AM04 e o engenheiro agrônomo de CE03. Portanto, é imprescindível que os professores leiam os textos ao planejarem suas atividades, otimizando a forma de utilização destes em sala de aula, podendo optar por uma estratégia de leitura crítica dos textos junto aos alunos, com o objetivo de promover um entendimento a respeito das condições de produção dos materiais de DC.

Conforme percebido em Martins, Cassab e Rocha (2001), Nascimento (2005) e Souza e Rocha (2014a), os textos de DC inseridos nos livros didáticos sofrem mudanças discursivas que alteram não só o significado, como deslocam a temática central e distorcem a visão de natureza da ciência transmitida originalmente, a fim de atender aos interesses dos autores dos livros didáticos. Um próximo passo para esta pesquisa consiste na análise detalhada destes textos a fim de verificar que modificações sofreram, de modo a auxiliar que professores possam estimular a leitura destes textos originais, não apenas os presentes nos livros didáticos, diretamente na fonte de pesquisa, desenvolvendo uma criticidade fundamental na formação dos jovens cidadãos. Assim, é fundamental entender que contribuições estes textos de DC inseridos nos livros didáticos podem trazer para o processo educativo, visto que foram escolhidos e modificados previamente com a intenção de conferir-lhes caráter pedagógico. 


\section{Referências}

ALFERES, S.; AGUSTINI, C. A escrita da divulgação científica. Horizonte Científico, Uberlândia, v. 2, n. 1, p. 1-23, 2008.

AMABIS, J. M.; MARTHO, G. R. Biologia em contexto. São Paulo: Moderna, 2013.

BELTRÁN NÚÑEZ, I. et al. A seleção dos livros didáticos: um saber necessário ao professor: o caso do ensino de ciências. OEI: revista iberoamericana de educación, sección de los lectores, Madrid, abr. 2003. Disponível em: < http://rieoei.org/did_mat1.htm>. Acesso em: 10 abr. 2017.

BRASIL. Ministério da Educação. Guia de livros didáticos: PNLD 2015: ensino médio: biologia. Brasília, 2014.

. Parâmetros curriculares nacionais: terceiro e quarto ciclos do ensino fundamental. Brasília, 2000.

BRÖCKELMANN, R. H. Conexões em biologia. São Paulo: Moderna, 2013.

BROWN , T. L. Making truth: metaphor in science. Champaign: University of Illinois Press, 2003.

CATALDI, C. A ciência na mídia impressa: a divulgação debate sobre transgênico. In: GOMES, M. C. A.; MELO, M. S. S.; CATALDI, C. Práticas discursivas: construindo identidades na diversidade. Viçosa: Arca, 2009. p. 43-63.

. A divulgação da ciência na mídia: um enfoque discursivo. In: GOMES, M. C. A.; MELO, M. S. S.; CATALDI, C. (Org.). Gênero discursivo, mídia e identidade. Viçosa: UFV, 2007. p. 155-164.

CÉSAR JR., S.; SEZAR, S.; CALDINI JR., N. Biologia. 11. ed. São Paulo: Saraiva, 2013.

CHARAUDEAU, P. E1 discurso de la información: la construcción del espejo social. Barcelona: Gedisa, 2003.

DAL PIAN, L. F.; ALVES, D. D. P. Desafios da divulgação científica em cobertura jornalística de desastre ambiental. Ciência \& Educação, Bauru, v. 19, n. 4, p. 929-946, 2013. FAVARETTO, J. A. Biologia: unidade e diversidade. São Paulo: Saraiva, 2013.

FERREIRA, L. N. A.; QUEIROZ, S. L. Características discursivas de artigos de divulgação científica relacionados à química. Revista Electrónica de Enseñanza de las Ciencias, Vigo, v. 11, n. 1, p. 21-42, 2012a.

. Textos de divulgação científica no ensino de ciências: uma revisão. Alexandria, Florianópolis, v. 5, n. 1, p. 3-31, 2012b.

FOUREZ, G. A construção das ciências: introdução à filosofia e à ética das ciências. São Paulo: UNESP, 1995.

FRAGA, F. B. F. F.; ROSA, R. T. D. Microbiologia na revista Ciência Hoje das Crianças: análise de textos de divulgação científica. Ciência \& Educação, Bauru, v. 21, n. 1, p. 199-218, 2015. 
GALIETA, T. Análise de discurso de textos do livro didático e de divulgação científica: caracterizando formações discursivas. In: ENCONTRO NACIONAL DE PESQUISA EM EDUCAÇÃO EM CIÊNCIAS, 9., 2013, Águas de Lindóia. Atas... Águas de Lindóia: ABRAPEC, 2013. p. 1-8.

GARRÉ, B. H.; HENNING, P. C. Visibilidades e enunciabilidades do dispositivo da educação ambiental: a revista Veja em exame. Alexandria, Florianópolis, v. 8, n. 2, p. 53-74, 2015.

GÓES, A. C. S.; OLIVEIRA, B. V. X. Projeto Genoma Humano: um retrato da construção do conhecimento científico sob a ótica da revista Ciência Hoje. Ciência \& Educação, Bauru, v. 20, n. 3, p. 561-577, 2014.

GOLDBACH, T.; EL-HANI, C. N. Entre receitas, programas e códigos: metáforas e idéias sobre genes na divulgação científica e no contexto escolar. Alexandria, Florianópolis, v. 1, n. 1, p. 153-189, 2008.

GOLDBACH, T.; EL-HANI, C. N.; MARTINS, R. C. A difícil tarefa da divulgação da idéia de gene em revistas de divulgação científica no Brasil. In: REUNIÃO DA RED POP, 9., 2005, Rio de Janeiro. Anais... Rio de Janeiro: Red POP, 2005.

GOMES, L. C.; FUSINATO, P. A.; NEVES, M. C. D. Análise da relação entre força e movimento em uma revista de divulgação científica. Ciência \& Educação, Bauru, v. 16, n. 2, p. 341-353, 2010.

GOMES, M. C.; DA POIAN, A. T.; GOLDBACH, T. Revistas de divulgação científica no ensino de ciências e biologia: contribuições e limitações de seu uso. In: ENCONTRO NACIONAL DE ENSINO DE CIÊNCIAS DA SAÚDE E DO AMBIENTE, 3., 2012, Niterói. Anais... Niterói: UFF, 2012. p. 1-13.

GONÇALVES, E. M. Os discursos da divulgação científica: um estudo de revistas especializadas em divulgar ciência para o público leigo. Brazilian Journalism Research, Brasília, v. 9, n. 2, p. 210-227, 2013.

GONÇALVES, E.; CALDAS, G.; PECHULA, M. Mídia e educação: reflexões sobre o uso pedagógico de textos de divulgação científica. In: REUNIÃO BIENAL DA REDE DE POPULARIZAÇÃO DA CIÊNCIA E DA TECNOLOGIA DA AMÉRICA LATINA E DO CARIBE (Red-Pop), 12., 2011, Campinas. Anais... Campinas: Unicamp, 2011. p. 1-10.

KEMPER, A.; ZIMMERMANN, E.; GASTAL, M. L. Textos populares de divulgação científica como ferramenta didático pedagógica: o caso da evolução biológica. Revista

Brasileira de Pesquisa em Educação em Ciências, São Paulo, v. 10, n. 3, p. 25-50, 2010.

JORGE, J.; ESCOLANO, A. C. M.; CASSIOLATO, A. M. R. Aspectos didáticos, laicos e científicos de artigos de divulgação científica de duas revistas de conteúdo geral. Ciência $\boldsymbol{\&}$ Educação, Bauru, v. 17, n. 4, p. 1015-1025, 2011.

LEGEY, A. P.; JURBERG, C.; COUTINHO, C. M. L. M. Educação científica na mídia impressa brasileira: avaliação da divulgação de biologia celular em jornais e revistas selecionados. Alexandria, Florianópolis, v. 2, n. 3, p. 35-52, 2009. 
LOBO, M.; MARTINS, I. Representações sobre alimentação e ciência em um texto de divulgação científica: implicações para a educação em ciências. Alexandria, Florianópolis, v. 6, n. 3, p. 3-26, 2013.

LOPES, S.; ROSSO, S. Bio. 2. ed. São Paulo: Saraiva, 2013.

MAINGUENEAU, D. Cenas da enunciação. São Paulo: Parábola Editorial, 2008.

MARTINS, I.; DAMASCENO, A. R. Uma análise das incorporações de textos de divulgação científica em livros didáticos de ciências. In: ENCONTRO DE PESQUISA EM ENSINO DE FÍSICA, 8., 2002, São Paulo. Atas... São Paulo: SBF, 2002. p. 1-10.

MARTINS, I.; CASSAB, M.; ROCHA, M. Análise do processo de re-elaboração discursiva de um texto de divulgação científica para um texto didático. Revista Brasileira de Pesquisa em Educação em Ciências, São Paulo, v. 1, n. 3, p. 1-9, 2001.

MARTINS, I.; NASCIMENTO, T.; ABREU, T. Clonagem na sala de aula: um exemplo de uso didático de um texto de divulgação científica. Investigações em Ensino de Ciências, Porto Alegre, v. 9, n. 1, p. 95-111, 2004.

MASSARANI, L.; MOREIRA, I. C. Not in our genes!: um estudo de caso com jovens do ensino médio no Rio de Janeiro. Alexandria, Florianópolis, v. 1, n. 1, p. 51-76, 2008.

MEGID-NETO, J.; FRACALANZA, H. O livro didático de ciências: problemas e soluções. Ciência \& Educação, Bauru, v. 9, n. 2, p. 147-157, 2003.

MILLAR, R. Towards a science curriculum for public understanding. School Science Review, Hatfield, v. 77, n. 280, p. 7-18, 1996.

MUSSATO, G. A.; CATELLI, F. Concepções epistemológicas em reportagens sobre ciência na mídia impressa brasileira e suas implicações no âmbito educacional. Investigações em Ensino de Ciências, Porto Alegre, v. 20, n. 1, p. 35-59, 2015.

NASCIMENTO, T. O discurso da divulgação científica no livro didático de ciências: características, adaptações e funções de um texto sobre clonagem. Revista Brasileira de Pesquisa em Educação em Ciências, São Paulo, v. 5, n. 2, p. 1-13, 2005.

Leituras de divulgação científica na formação inicial de professores de ciências. 2008. 376 f. Tese (Doutorado em Educação Científica e Tecnológica) - Centro de Ciências da Educação, Universidade Federal de Santa Catarina, Florianópolis, 2008.

NASCIMENTO, T. G.; REZENDE JR., M. F. A produção sobre divulgação científica na área de educação em ciências: referenciais teóricos e principais temáticas. Investigações em Ensino de Ciências, Porto Alegre, v. 15, n. 1, p. 97-120, 2010.

OLIVEIRA, L. et al. A divulgação científica de temas de saúde: análise de um impresso.

Ciência em Tela, Rio de Janeiro, v. 3, n. 1, p. 1-9, 2010.

ORLANDI, E. Análise de discurso: princípios e procedimentos. Campinas: Pontes, 2002.

. Divulgação científica e efeito leitor: uma política social urbana. In:

Discurso e texto: formulação e circulação dos sentidos. Campinas: Pontes, 2001. p. 149-162. 
PARKINSON, J.; ADENDORFF, R. The use of popular science articles in teaching scientific literacy. English for Specific Purposes, Oxford, v. 23, n. 4, p. 379-396, 2004. PEREIRA, A. G.; TERRAZZAN, E. A. A multimodalidade em textos de popularização científica: contribuições para o ensino de ciências para crianças. Ciência \& Educação, Bauru, v. 17, n. 2, p. 489-503, 2011.

ROCHA, M. Textos de divulgação científica na sala de aula: a visão do professor de ciências. Revista Augustus, Rio de Janeiro, v. 14, n. 29, p. 24-34, 2010.

QUEIROZ, S. L.; FERREIRA, L. N. A. Traços de cientificidade, didaticidade e laicidade em artigos da revista "Ciência Hoje" relacionados à química. Ciência \& Educação, Bauru, v. 19, n. 4, p. 947-969, 2013.

SOUSA, A. C. et al. A presença do tema eugenia em uma revista de divulgação científica no período de 1990 a 2009. Revista Brasileira de Pesquisa em Educação em Ciências, São Paulo, v. 14, n. 1, p. 31-53, 2014.

SOUZA, P. H. R.; ROCHA, M. B. Abordagem da mídia impressa em periódicos da área de ensino de ciências. In: SIMPÓSIO NACIONAL DE ENSINO DE CIÊNCIA E TECNOLOGIA, 4., 2014, Ponta Grossa. Anais... Ponta Grossa: UTFPR, 2014a.

. Análise do processo de reelaboração discursiva na incorporação de um texto de divulgação científica no livro de ciências. Revista Brasileira de Educação em Ciência e Tecnologia, Ponta Grossa, v. 7, n. 1, p. 53-69, 2014b.

Caracterização dos textos de divulgação científica inseridos em livros didáticos de biologia. Investigações em Ensino de Ciências, Porto Alegre, v. 20, n. 2, p. 126-137, $2015 a$.

Sistemática filogenética em revista de divulgação científica: análise da Scientific American Brasil. Alexandria, Florianópolis, v. 8, n. 1, p. 75-99, 2015b.

SULAIMAN, S. N. Educação ambiental, sustentabilidade e ciência: o papel da mídia na difusão de conhecimentos científicos. Ciência \& Educação, Bauru, v. 17, n. 3, p. 645-662, 2011.

ZAMBONI, L. M. S. Cientistas, jornalistas e a divulgação científica: subjetividade e heterogeneidade no discurso da divulgação científica. Campinas: Autores Associados, 2001.

Artigo recebido em: 08/06/2016. Aceito em: 23/10/2016.

Endereço para contato: Centro Federal de Educação Tecnológica Celso Suckow da Fonseca, Avenida Maracanã, 229, Maracanã, CEP 20271-110, Rio de Janeiro, RJ, Brasil. 